\title{
BRB SYSTEM STABILITY CONSIDERING FRAME OUT-OF-PLANE LOADING AND DEFORMATIONZONE
}

\author{
Gregory A. MacRae ${ }^{1}$, Chin-Long Lee ${ }^{2}$, \\ Saul Y. Vazquez-Colunga ${ }^{3}$, Jian $\mathrm{Cui}^{4}$, Saeid Alizadeh ${ }^{5}$ \\ and Liang-Jiu Jia ${ }^{6}$
}

(Submitted January 2020; Reviewed April 2020; Accepted August 2020)

\begin{abstract}
A simple and economical design approach is described for a BRB system, consisting of a BRB within a steel frame, subject to in-plane and out-of-plane seismic displacements. The approach avoids out-of-plane system or brace instability while allowing large frame out-of-plane deformations and desirable BRB axial performance. It also limits the compressive/tension force ratio. It is based on the simple concept that a brace will be stable with two moment-releases (hinges) but that an out-of-plane buckling mechanism may occur with more than two. The hinges are detailed as specified deformation zones (SDZs) at the brace ends. The hinges use a plate which can yield about its weak axis during out-of-plane movement. Simple methods to assess the stability of the brace itself (between hinges) are developed, an example is provided illustrating how the monotonic deformation demand of the simple plate hinge can be assessed, and detailing recommendations are made to restrict the deformation of the boundary elements at the brace ends.
\end{abstract}

\section{INTRODUCTION}

Buckling Restrained Braces (BRBs) have become popular in frames in seismic resisting regions. BRB frames tend to be stiffer than moment frames, have a well-matched capacity to the demand (resulting in low system overstrength), similar tensioncompression performance, and can dissipate significant amount of energy. BRBs have performed well in some experimental tests. However, concerns exist about the implementation of BRBs into frame systems for a number of reasons [1-4]. In addition, a variety of different failure types have been reported $[5,6]$. Two significant issues are:

1. Gusset plate design, where Westeneng et al. [7] showed that current design techniques proposed by AISC [8] may be non-conservative. This was already recognised earlier by Japanese and Taiwanese researchers who have alternative/additional requirements to those of AISC for gusset plate buckling length, and they require gusset plate edge stiffeners. Most Western countries follow AISC design procedures directly and do not use gusset plate edge stiffeners because of their extra cost; and

2. The performance under earthquake shaking causing out-ofplane deformations. Most common test protocols for evaluating the acceptability of a brace require in-plane testing only, in spite of the fact that earthquake shaking can cause out-of-plane deformation. Such deformation can cause moments within the brace, and increases of brace compressive force. Out-of-plane tests of ty pical braces have caused increases of BRB compressive force by up to $30 \%$ above that from in-plane tests [9]. Associated analy ses have indicated that chamfering the edges of plates which are part of the core transition zone (CTZ) within the casing can decrease these compression forces since the plates have less ability to dig into the casing material). Moments also caused a reduction in BRB performance in terms of cumulative displacements [10].
Both a low, and a high, stiffness of the elements outside the casing (i.e. the outside casing zone (OCZ) including the core outside the casing, gusset plate and boundary element) may be problematic in terms of performance. If the OCZ is stiff, then yielding during out-of-plane displacements may compromise the BRB ability to perform well under subsequent in-plane displacements. Conversely, if the OCZ is flexible, then buckling may occur due to in-plane effects. It is not clear whether or not there is always a "sweet spot" for OCZ stiffness that will satisfy both considerations.

The issues described above relate to the performance of the $\mathrm{BRB}$ sy stem, rather than just to the BRB itself. As a result, BRB manufacturing companies have not spent much effort to address these issues. Some of these issues have been previously raised $[11,12]$ and specific design guidance has been developed in Japanese [13]. However, the procedures are not simple to apply in practice. Zaboli et al. [14] have proposed a strength based gusset plate design approach, while the buckling likelihood is related to stiffness. Furthermore, none of the current proposals for BRB system design explicitly consider (i) the need for column rotational restraint, or (ii) the specific zone of permitted yielding.

A smart method to mitigate the out-of-plane deformation effects on a BRB itself is to place a perfect pin/hinge at each end of the brace [15]. A perfect pin carries almost no moment. The inclusion of such a "deformation zone" in a well-designed brace solves issues with commonly used gusset plate connections by:

1. ensuring that rotation due to out-of-plane loading is concentrated in a specific location and yielding will not occur near the casing which could adversely affect the axial deformation of the brace,

2. allowing large axial forces to be carried without the possibility of instability over that region,

\footnotetext{
${ }^{1}$ Corresponding Author, Associate Professor, University of Canterbury, Christchurch,NZ, gregory.macrae@canterbury.ac.nz.(Member)

2 Senior Lecturer, University of Canterbury, chin-long.lee@canterbury.ac.nz

${ }^{3}$ PhD Candidate, University of Canterbury, saul.vazquezcolunga@pg.canterburv.ac.nz

${ }^{4}$ PhD Candidate, University of Canterbury, jian.cui@pg.canterbury.ac.nz

${ }^{5}$ BECA Consultants, Hamilton, New Zealand, saeid.alizadeh@beca.com

${ }^{6}$ Associate Professor, Tongji University, Shanghai, China, li_jia@tongji.edu.cn
} 
3. allowing large out-of-plane deformations without detrimentally affecting the BRB performance, and

4. limiting the moments applied to the brace so that the brace itself is subject only to in-plane loading.

However, the implementation of specifically manufactured, or proprietary, perfect pins may be costly. Furthermore, while demands on the brace are reduced, special and explicit considerations are required to prevent system issues as a result of the strength and stiffness (and hence buckling likelihood) of the elements on the far side of the pin from the brace (i.e. the outside pin zone, $O P Z$ ).

Informal discussions with industry practitioners indicate that the lack of agreement on a suitable agreed approaches to design frames with BRBs considering system stability and control of the yielding in NZ has been one of a number of factors contributing to cancellation of the development of national design recommendations for $\mathrm{BRB}$ systems, and also to a reduction in the use of BRBs in NZ structures.

It may be seen from the discussion above that for BRBs to behave in desirable and dependable manner under both in-plane and out-of-plane loading, appropriate design procedures are needed. This paper seeks to address this need by seeking answers to the following questions:

1. What is required for a BRB frame system under in-plane loading to undergo large out-of-plane drifts without out-ofplane drift damage or a buckling failure?

2. Can a new concept be developed to allow the system to experience large bi-directional horizontal drifts?

3. Can design methods be developed for the BRB itself and for the BRB system?

4. What is the out-of-plane deformation capacity of such a system?

5. What are some key details for good system performance?

\section{BRB DEFORMATION AND BUCKLING}

If one or both ends of the BRB have some restraint against rotation, out-of-plane frame deformations can impose loads on the BRB end zones, gusset plates, and column. Such loads can result in yielding within the system, and the possibility of poor behaviour during subsequent in-plane and out-of-plane cyclic deformations.

By placing perfect pins at the outer end of the BRB core transition zone (CTZ), such as suggested by Bruneau and Wei [15], the BRB can remain straight during out-of-plane deformation as shown in Figure 1. However, this behaviour is only possible if the OPZ elements are relatively stiff and do not buckle under the forces applied from the BRB. In addition, OPZ elements must be strong enough to resist the bending caused by the compressive axial force in the BRB. Analysis of such a system involves assessing the stability of:

1. the region between pins, inside pin zone (IPZ), using a methodology similar to that of Alizadeh [16], and

2. the OPZ

If there are no pins but the boundary elements (gusset plate, beam or column) are flexible (i.e. $k_{\theta, \text { frame }}=0$ ) as shown in Figure 2, out-of-plane deformation may occur without compromising the ability of the BRB to carry axial force. However, flexible boundary elements are not generally desirable in practice, because other modes of failure involving column twisting may occur.

If out-of-plane deformation causes either of the deformation modes shown in Figure 1 or 2, then the axial strength of the $\mathrm{BRB}$ remains the same as the in-plane case. However, the frame in-plane horizontal force capacity, due to the BRB resistance only, decreases. The frame in-plane horizontal force capacity is cosine $\theta$ times that of the brace if it remained in-plane, where $\theta$ is the angle shown in Figure 2. Since out-of-plane drifts are normally small, cosine $\theta$ is close to unity, and there is little strength reduction.

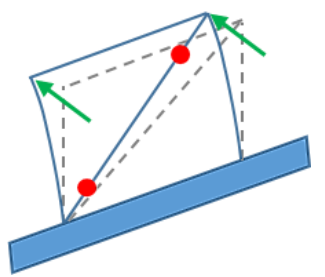

(a) Overall Frame

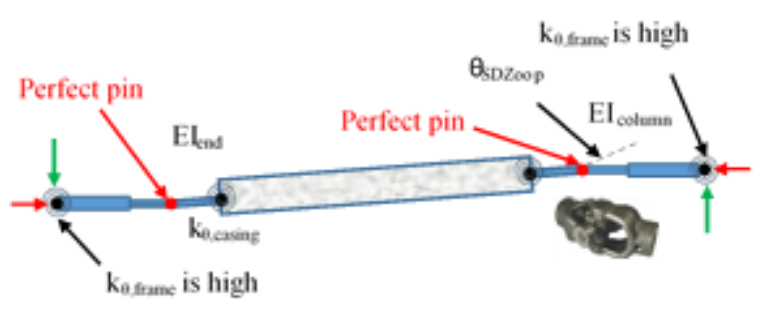

(b) View of BRB

Figure 1: Out-of-plane frame deformation of idealised BRB with end pins and rigid boundaries.

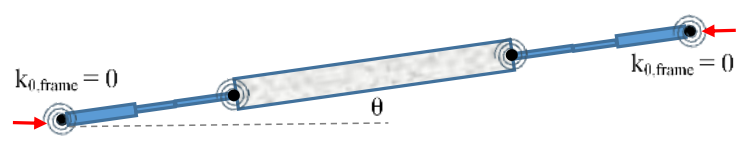

Figure 2: Out-of-plane frame deformation of idealised BRB with flexible boundaries.

If out-of-plane deformation causes either of the deformation modes shown in Figure 1 or 2 , then the axial strength of the $\mathrm{BRB}$ remains the same as the in-plane case. However, the frame in-plane horizontal force capacity, due to the BRB resistance only, decreases. The frame in-plane horizontal force capacity is cosine $\theta$ times that of the brace if it remained in-plane, where $\theta$ is the angle shown in Figure 2. Since out-of-plane drifts are normally small, cosine $\theta$ is close to unity, and there is little strength reduction.

However, if the boundary elements are perfect pins (e.g. $k_{\theta, f r a m e}$ $=0$ ), and perfect pins also exist within the brace, then zero axial force can be carried by the system because it forms a global buckling mechanism as shown in Figure 3. A minimum of three hinges are required for a mechanism. (This is the same for beams, which if they contain 3 pins along their length, form a mechanism and they are unable to sustain lateral load.) For good behaviour it is therefore imperative that there are no more than 2 pins/hinges along over the length.

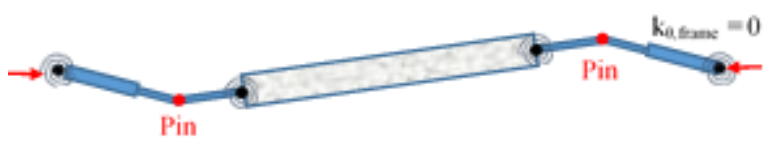

Figure 3: Out-of-plane frame deformation of idealised BRB with end pins and flexible boundaries. 


\section{PROPOSED BRB S YSTEM DESIGN CONCEPT}

The proposed concept is based on Bruneau and Wei [15] where perfect pins were placed at the BRB ends as shown in Figure 1. This allows lateral movement, but the system is stable. It also puts no moment into the BRB itself. However, simply using perfect pins is not sufficient because:

- A lateral stability failure may occur if the boundary elements (gusset plate, column/beam. and their restraints) have low stiffness, as shown in Figure 3.

- Perfect pins are expensive and constructability tolerances may be difficult.

To reduce construction cost, instead of using perfect pins/hinges, "poor man's pins" referred to as "specified deformation zones (SDZs)" are proposed. These SDZs are regions of localised yielding in steel plate located at both ends of the BRB. After reaching their flexural strength SDZs freely allow rotation during frame out-of-plane drifts. SDZs should:

1. easily carry the direct axial force from in-plane loading to the brace,

2. be short enough to not buckle over their length,

3. be long enough to avoid excessive strain demands during expected repeated out-of-plane deformations, and

4. be weak in flexure to limit moments which could detrimentally affect the BRB and the brace-column joint.

Simple details are given in Figure 4 with the SDZ placed outside the BRB casing a distance so that it does not enter the casing during expected axial deformations. The SDZ may be within the brace core itself as shown in Figure 4a (i.e. the sequence is core yield zone (CYZ), core transition zone (CTZ), SDZ, core connection zone (CCZ), and outside pin zone (OPZ)), or within the gusset plate (i.e. the sequence is CYZ, CTZ, CCZ, SDZ, and OPZ), as shown in Figure 4b. Variations are also possible. Having the SDZ in the gusset plate may provide the most versatility because the gusset plate thickness and width can be selected appropriately, and it may be easier to add stiffeners. For simplicity, further discussion in this paper concentrates on the gusset plate SDZ shown in Figure $4 \mathrm{~b}$. A plan of such a member is given in Figure 5.

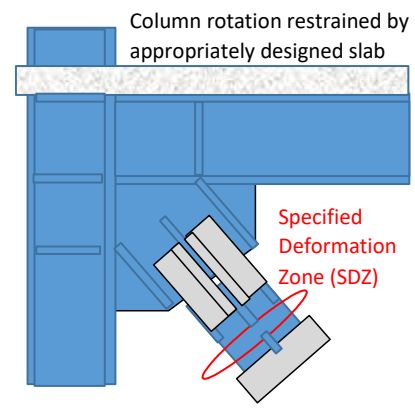

(a) In BRB

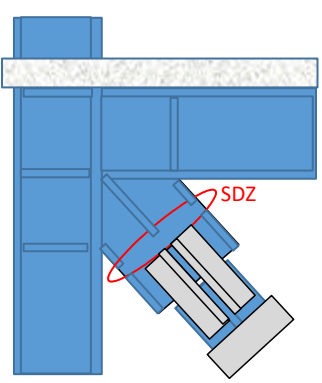

(b) In Gusset Plate
Figure 4: Specified deformation zones (SDZs) for out-of-plane bending.

\section{DES IGN CONSIDERATIONS}

\section{Specified Deformation Zone (SDZ) S train Demands}

Strains in the SDZ result from axial force, flexural, and cyclic effects. The strain due to axial force, Eaxial, should not be too high or the monotonic flexural strain, glexural, resulting from axial and bending effects will cause the total SDZ monotonic strain, $\varepsilon_{S D C \text {,monotonic }}\left(=\varepsilon_{\text {axial }}+\right.$ glexural $)$ to be too large. Here, $\beta$ is defined as $\varepsilon_{a x i a l}$ divided by the yield strain, \&. Also, $\varepsilon_{\text {flexural }}=\varnothing\left(\frac{t}{2}\right)$

$\varepsilon_{\text {flexural }}=\frac{\theta_{S D Z o o p}}{l_{S D Z}}\left(\frac{t}{2}\right)$

where $\phi$ is the maximum curvature, $t$ is the SDZ plate thickness, $\theta_{S D Z o o p}$ is the maximum SDZ rotation as shown in Figure 1 , and $l_{S D Z}$ is the SDZ length.

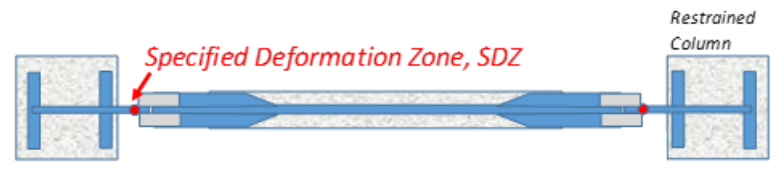

(a) BRB and end zones (not all connection plates shown)

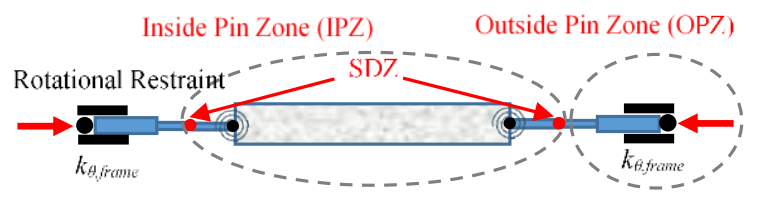

(b) Simple Model

Figure 5: Plan with specified deformation zones and $k_{\theta}$ frame $\rightarrow \infty$ (not all plates shown).

The rotation $\theta_{S D Z o o p}$ may be estimated:

1. from kinematic considerations as the frame moves to its maximum likely out-of-plane drift, $(\Delta h)_{\max }$, or

2. as the interstorey out-of-plane displacement divided by the distance between SDZs (- this is likely to be conservative), or

3. as the inelastic interstorey displacement demand divided by the distance between SDZs plus the elastic SDZ rotation, or

4. another reasonable approximation.

For routine design, method 2 may be simplest. It is also noted here that the interstorey drift per se, is not always important. For example, it is possible to achieve significant interstorey drifts if the entire building undergoes rigid body rotation by rocking about the base on one side causing uplift on the other side, but this will not impose any demand on the BRBs.

The cyclic axial strain increases rapidly for a member subject to repeated y ielding flexural strains in both directions of loading for an element in constant tension or compression [17]. For a typical frame, significant out-of-plane bending may occur during positive axial loading, or negative axial loading, or both. Since it is difficult to predict this without special study, it is prudent to limit the total SDZ strain, $\varepsilon_{S D C \text {, monotonic }}=\varepsilon_{\text {axial }}+$ glexural, to a small level. This can be likely achieved by providing controlling the dimensions and plate size in the SDZ.

Preliminary maximum values of $\beta=0.40$ and $\varepsilon D C$,monotonic of $1.5 \%$ are suggested as possible reasonable limits until better information becomes available.

For example, if $(\Delta h)_{\max }=1.5 \%, \xi=0.0015, \beta=0.30$ say, and aspect ratio, $l_{S D Z} / t$, is 2 say, then if it is assumed that $\theta_{S D Z o o p}=$ $(\Delta h)_{\max }=1.5 \%$, then

$$
\begin{aligned}
\varepsilon_{S D C, \text { monotonic }} & =\beta \varepsilon_{y}+\theta_{\text {SDZ oop }} \frac{\left(\frac{t}{2}\right)}{l_{S D Z}} \\
& =0.30 \times 0.0015+0.015 \times(1 / 2) / 2 \\
& =0.30 \times 0.0015+0.015 \times(1 / 2) / 2 \\
& =0.00045+0.00375 \\
& =0.00420=2.8 \varepsilon_{y}
\end{aligned}
$$


Here, since SSC monotonic $=0.420 \%$ is less than $1.5 \%$, this is satisfactory.

\section{Specified Deformation Zone (SDZ) Local Buckling}

Local buckling may occur within the SDZ if its aspect ratio, $l_{S D Z} / t$, is too high. Therefore, $l_{S D Z} / t$ should not be too large. A value of $l_{S D Z} / t$ of 2 is suggested in AISC341 [8] in Figure CF2.19, based on Lee and Goel [18], for concentrically braced frames (CBFs) with straight yield lines in the gusset plate perpendicular to the brace axis. For such CBFs, bending can occur in the gusset plate under in-plane loading as the brace buckles out-of-plane. Other yield patterns are available, but these increase the moments. Until further information is available, a straight line with $l_{S D Z} / t$ of 2 is recommended.

\section{IPZ Stability}

The brace between the SDZs, shown as the inside pin zone (IPZ) in Figure 5b, must be designed against buckling. The critical condition is when there is no rotational restraint at the SDZ as a result of yielding there, so the length over which buckling occurs is simply the distance between SDZs. In order to conduct the buckling analysis, it is necessary to know the flexural stiffness of the casing and the end of the casing.

The casing end minimum rotational stiffness, $k_{\theta \text {,casing }}$ in Figure $6 \mathrm{a}$, resulting in the lowest buckling load, should be obtained experimentally. This may be obtained by a three-point loading test, where a BRB is simply supported (providing support transverse to the direction of the member axis) at one end of the casing as well as near the far connection of the BRB. Transverse loading is applied to the BRB near the casing end close to the supported connection. The displacement obtained at the loading position may be compared to that from a model to establish the stiffness of the rotational spring at the casing end, $k_{\theta, \text { casing. }}$ This testing should be conducted after repeated axial testing with the brace is in its most extended position to obtain the most critical (i.e. lowest) $k_{\theta \text {,casing }}$ values. The stability analy sis may follow Westeneng et al. [7]. For the stability analysis also, the brace should be considered at its maximum extension because longer members have lower buckling strengths.

A modelling simplification may be obtained by replacing both the casing, and the casing end rotational stiffness, $k_{\theta, \text { casing }}$, by a shorter length of casing as shown in Figure 6b. In this case, only two stiffnesses and two lengths need to be considered, and these are those of the BRB casing and the end zone [9]. Experimental calibration is needed to ensure reasonable results. As an initial estimate, and until better information is available, the reduction at each end, $\Delta_{\text {casing }}$, could be taken as equal to the casing diameter, $D_{\text {casing, }}$ as shown in Figure 6 . The lowest buckling mode may be found using stability concepts, and then simplified for design, following Alizadeh et al. [16]

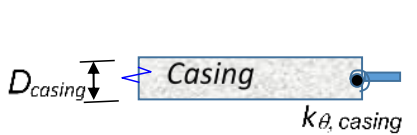

(a) Rotational spring

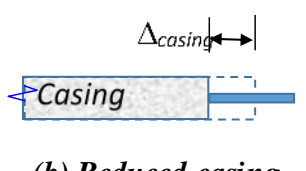

(b) Reduced casing length

\section{Figure 6: Modelling casing end connection.}

The IPZ in Figure 5, under axial force can deform in both a (1) symmetric, and an (2) anti-symmetric, buckling modes, as shown in Figure 7. Based on simple column buckling theory and stability concepts, the anti-symmetric buckling mode results in higher critical axial loads [16]. Therefore, only the symmetric buckling mode is further considered. Equation 1 estimates the first mode elastic buckling load, $P_{c r l}$, as there is no closed-form solution. Here $E I_{\text {casing }}$ is the effective flexural stiffness of the cased zone (often estimated as that of the casing alone) for the material considered; $E I_{\text {endzone }}$ is the effective flexural stiffness of the end zone; $L_{\text {casing }}$ is the effective length of casing considering the effect of the reduced casing length as shown in Figure 6; $L_{\text {endzone }}$ is the effective length of end zone where the brace is considered to be at its maximum extension; $L=L_{\text {casing }}+2 L_{\text {endzone }}$ is the total member length. An approximate equation for $P_{c r l}$ has been developed over the practical range of parameters when $L_{\text {casing }} / L$ is in the range 0 to 1 , and $E I_{\text {endzone }} / E I_{\text {casing }}$ is in the range 0 to 1 . It is accurate and generally conservative. It may also be noted that as $L_{\text {casing }}$ tends to:

- zero (i.e. $L_{\text {casing }} \rightarrow 0$ ), then $\alpha \rightarrow r=E I_{\text {endzone }} / E I_{\text {casing }}$, and $P_{c r l}$ tends to the Euler value for EI endzone over the total member length $L$.

- the full member length (i.e. Lendzone $\rightarrow 0$ ), then $\alpha \rightarrow 1$ and $P_{c r l}$ tends to the Euler value for $E I_{\text {casing }}$ over the total member length (which is $L_{\text {casing }}$ in this case).

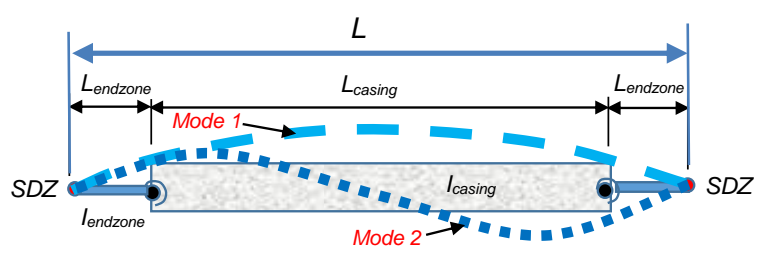

Figure 7: Buckling modes of brace between SDZs in IPZ.

It should be noted that when $E I_{\text {endzone }}=E I_{\text {casing }}$, i.e. $r=1$, then the buckling axial force differs slightly from the expected condition of the Euler buckling load for a uniform member. However, the error in $P_{c r l}$ ranges between $-3.7 \%$ and $1.3 \%$ within the likely range of $s$, which is considered negligible.

$P_{c r 1}=\frac{\alpha \pi^{2} E I_{\text {casing }}}{L^{2}}$

$\alpha=\alpha_{0} f$

$\alpha_{0}=\frac{r}{r s^{2}+(1-s)^{2}+2.4 r s(1-s)}$

$f=\frac{2}{1+\sqrt{1-\theta}}$

$\theta=\frac{2.3 r s(1-s)\left(1-s^{2}\right)}{\left(r s^{2}+(1-s)^{2}+3 s(1-s)\right)^{2}}$

$r=\frac{E I_{\text {endzone }}}{E I_{\text {casing }}}$

$S=\frac{L_{\text {casing }}}{L}$

It is suggested that, until a more definitive approach is available, that the maximum compressive axial force demand be less than $P_{c r l} / 3.5$ (or $0.286 P_{c r l}$ ). This value is consistent with the NZ Steel Standard [19] Clause 4.9.1 where it is used for a different purpose. Here, it is used to account for the many uncertainties associated with stability including residual stresses, fabrication tolerances, out-of-straightness, out-ofplane displacement magnitude, member/material overstrength, and dy namic effects.

\section{OPZ S tability}

The outside pin zone (OPZ) (i.e. the connection and boundary elements (e.g. beams and columns) shown in Figure 5 should be stiff and not buckle when the SDZ is subject to high axial force. That is, a failure mechanism such as that shown in Figure 3 should be avoided. The actual behaviour is complex.

It is assumed below that the element may be modelled as a cantilever as shown in Figure 8. The cantilever is assumed to have end rotational restraint at the intersection between the line 
of the brace and the floor slab. This rotational restraint is provided in the plane of the frame but perpendicular to the brace axis. The cantilever itself (the green element in Figure 8) is considered to extend from the SDZ to the end restraint point, with a length $L_{\text {strut }}$.

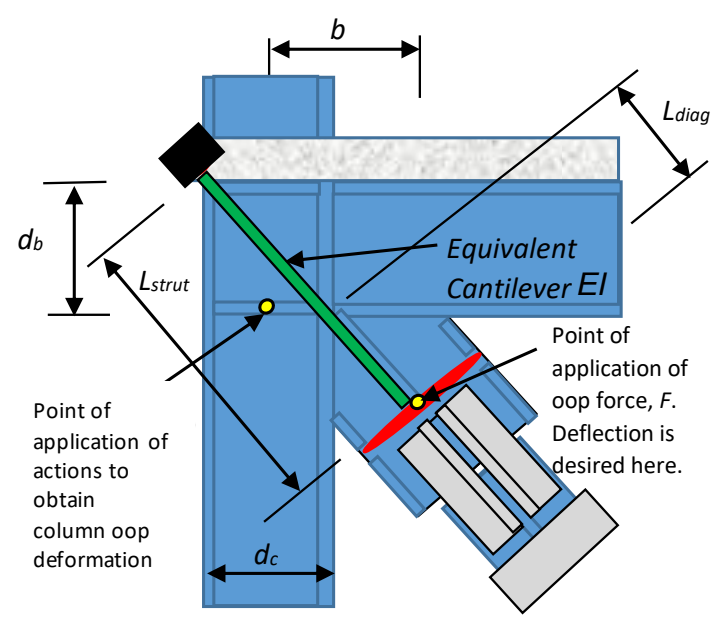

Figure 8: Equivalent fixed base cantilever member at joint.

The stiffness of many components contribute to the cantilever end restraint. These include:

1. floor slab restraint of column out-of-plane (i.e. lateral/torsional) movement,

2. slab horizontal restraint of beam top flange,

3. floor slab torsional restraint of the beam top flange about the longitudinal axis of the beam, which depends on the slab thickness, reinforcing, end conditions, slab type (e.g. continuous, hollow-core, or cold-formed steel decking), slab orientation, connection of floor to slab, slab span, and connection of neighbouring beams,

4. column restraint provided at adjacent floors/levels. However, if similar deformations occur at adjacent floors, they may not provide restraint, or they may even increase the bucking propensity,

5. column restraint as a result of girts (if they exist) between columns. Restraint provided depends on girt continuity, and connection details.

The stiffness provided in some of the components above may be difficult to assess for the general case. For simplicity, in the discussion below, it is assumed that only cases (1) and (2) above are active. That is, the floor slab can be relied upon to restrict column out-of-plane deformation and the top of the beam flange is restrained horizontally.

A procedure is also required to estimate the cantilever flexural section stiffness, EI. Several parallel load paths may be considered related to this. These include:

1. Load Path 1, as shown in Figure 9. This figure shows the deformation associated with out-of-frame movement of the SDZ only. Here an arbitrary applied out-of-plane force at the $\mathrm{SDZ}, F$, causes bending of the gusset plate stiffener connected to the beam bottom flange in Figure $4 \mathrm{~b}$. Deformation occurs within the column (as shown in Figure 9b), beam (via twisting as shown in Figure 9c), and gusset plate stiffener (Figure 9d).

To engage the whole beam to resist torsion (rather than just the bottom flange itself), a vertical stiffener is required between the beam flanges, as shown in Figure 4b. The beam then undergoes torsion about its top flange connection to the slab (where it is assumed to have lateral fixity to the beam slab). If the beam end is fully fixed to the column, then warping forces will also contribute to the beam torsional stiffness. Beam torsion causes the column out-ofplane bending (Figure 9b). Since buckling may also occur at adjacent floors, Equation 4 may approximate the column out-of-plane flexural stiffness, $M / \theta$. Here $\left(E I_{o o p}\right)_{c o l}$ is the column out-of-plane bending stiffness, and $L_{\text {colabove }}$ and $L_{\text {col,below }}$ are the interstorey height above and below the level considered respectively. Other equations may be developed from engineering mechanics to consider beam torsional and gusset plate stiffness effects and combined with this column weak-axis bending effect to obtain the lateral deflection resulting from a force applied at the SDZ.

$M / \theta=\frac{2\left(E I_{\text {oop }}\right)_{\text {col }}}{L_{\text {col,above }}}+\frac{2\left(E I_{\text {oop }}\right)_{\text {col }}}{L_{\text {col, below }}}$

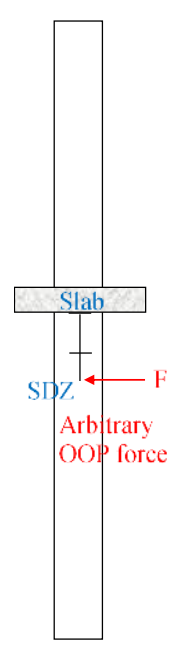

(a) Column

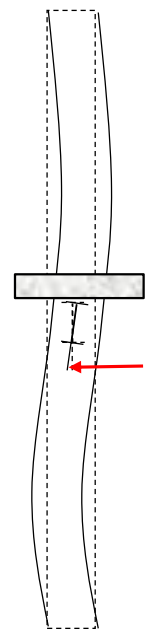

(b) Column Deformation

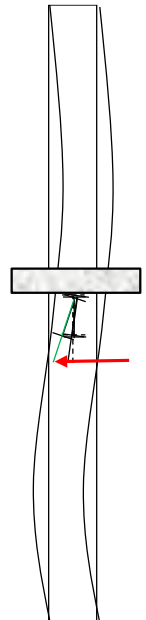

(c) Plus

Beam

Deformation

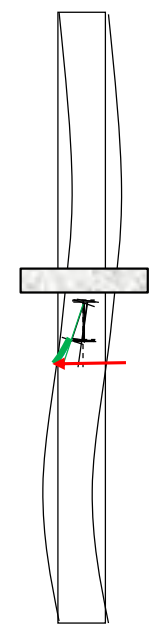

(d) Plus

Gusset Plate Deformation
Figure 9: Load Path 1 - Elevation-Beam torsion.

2. Load Path 2, as shown in Figure 10. Here the applied force at the SDZ causes bending of the lower gusset plate stiffener in Figure 4b. This stiffener connects to the column flange. To engage the whole column to resist torsion (rather than the flange itself), a horizontal stiffener is required between the column flanges, as shown in Figure $4 \mathrm{~b}$. Since the column is continuous, warping will contribute to the torsional stiffness. The reinforced concrete floor slab, which wraps around the column, resists the torsion. Equations to determine the stiffnesses of the elements may be developed using simple engineering principles.

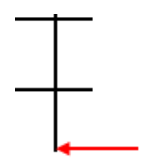

(a) Column Plan

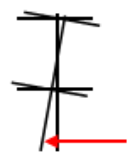

(b) Column

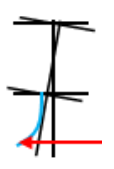

(c) Plus GP Deformation

\section{Figure 10: Load Path 2 -Plan-Column deformation.}

3. Load Path 3. Here the applied force at the SDZ causes bending of the central gusset plate stiffener in Figure $4 \mathrm{~b}$. This stiffener is connected to the column flange-beamflange intersection. The column is subject to torsion resisted by the reinforced concrete floor slab wrapping around the column. Deformation mechanisms include:

i. Column torsion effect, $\Delta_{\text {twist }}$. The torque causing this torsion, $T$, is equal to the out-of-plane force at the centre of the SDZ, $F$, multiplied by the horizontal distance to 
the centre of the column, $b$. This torque is applied to the centre of the column section at the level of the beam bottom flange causing column twist. Because the applied torque position is close to the slab above, it may be conservatively assumed that all torsion is carried above the position of torque application (i.e. the beam bottom flange level), and that the length of column resisting twist is equal to the beam depth because torsion is restrained by the slab. The twist angle, $\phi$, for a member is subject to equal and opposite torque at each end, $T$, where both ends of the member are restrained against torsion and warping, is given by Hughes et al. [20] in Equation 5. Here, the member length is $d_{b}, G$ is the shear modulus (80GPa for steel), $I_{T}$ is the torsion constant, $a$ is given by Equation 6, $I_{w}$ is the warping constant, and $E$ is the elastic modulus (200GPa for steel).

$\emptyset=\left[\frac{F b a}{G I_{T}}\right]\left\{\tanh \left(\frac{d_{b}}{2 a}\right) \cosh \left(\frac{d_{b}}{a}\right)-\tanh \left(\frac{d_{b}}{2 a}\right)+\frac{d_{b}}{a}-\right.$

$\left.\sinh \left(\frac{d_{b}}{a}\right)\right\}$

$a=\sqrt{\frac{E I_{W}}{G I_{T}}}$

The out-of-plane deflection at the SDZ due to twist, $\Delta_{\text {twist }}$, is:

$\Delta_{t w i s t}=\emptyset b$

ii. Column lateral displacement, $\Delta_{\text {lat }}$. This is due to $F$ applied at the column centreline at the level of the beam bottom flange. The out-of-plane (oop) deflection at this point is given by Equation 8 [21] where $L$ is the interstorey height between slabs, and $E I$ is the out-ofplane column section flexural stiffness. The second term is added as a slightly conservative estimate of the shear deformation for the very short length of the column above the point of load application, where $A_{s}$ is the column section out-of-plane shear area.

$\Delta_{l a t}=\frac{F\left(L-d_{b}\right)^{2} d_{b}^{2}}{3 E I L}+\frac{F L}{G A_{s}}$

iii. Diagonal stiffener out-of-plane displacement, $\Delta_{\text {diag }}$. The diagonal stiffener displacement carries the load to the column at the level of the beam bottom flange. However, the beam bottom flange stiffener also carries load to the centre of the column (from which the twist and lateral deflections are computed as shown above). If $E I$ of the diagonal stiffener, $E I_{\text {diag }}$, and beam bottom flange stiffener are similar, then the deflection may be considered to come from a member with a section flexural stiffness, $E I_{\text {diag }}$, and a total length equal to the column length plus half of the column width (i.e. $L_{\text {diag }}$ $\left.+d_{c} / 2\right)$. Here, the out-of-plane displacement is given in Equation 9, and $A_{s, \text { diag }}$ is the diagonal stiffener shear area:

$\Delta_{\text {diag }}=\frac{F\left(L_{\text {diag }}+\frac{d_{c}}{2}\right)^{3}}{3 E I_{\text {diag }}}+\frac{F\left(L_{\text {diag }}+\frac{d_{c}}{2}\right)}{G A_{S, \text { diag }}}$

The total deflection here is:

$\Delta_{\text {tot }}=\Delta_{\text {twist }}+\Delta_{\text {lat }}+\Delta_{\text {diag }}$

The load path total stiffness is therefore

$k=\frac{F}{\Delta_{\text {tot }}}$

The flexural section properties of the equivalent flexural cantilever are in Equation 12. This cantilever approximation may be used in the stability analy sis.

$E I_{\text {strut }}=\frac{k L_{\text {strut }}{ }^{3}}{3}$
For design, sufficient stiffness needs to be provided via the different load paths. Since the different load paths are in parallel, the stiffness from each load path can be summed together directly to obtain the resistance to deflection for a specified SDZ lateral force. Therefore, if stiffness provided by some load paths is high, then some other load paths may be conservatively ignored. For example, if Load Path 3 is sufficient to prevent lateral buckling of the gusset plate/boundary element system (i.e. the components on the column side of the SDZ), then Load Paths 1 and 2 may be ignored. In this case, the additional stiffener plates provided between the flange tips to activate torsion over the full beam/column section shown in Figure $4 \mathrm{~b}$ are not required, as shown in Figure 8. After elastic buckling force is obtained from the load path(s) considered, the maximum compressive force is $1 / 3.5$ times this value as described in brace stability considerations.

The equivalent fixed-end cantilever as shown in Figure 8 and developed using principles similar to that described under Load Path 3 above, is convenient for analysis. The cantilever effective length may be 2.0 for symmetric buckling (as shown in Figure 11a) or greater than 2 for anti-symmetric buckling mode (as shown in Figure 11b) because the BRB member applies a post-buckling force at the end of the cantilever at an angle from the undeformed cantilever member angle. The exact equation for this case is given by Alizadeh et al. [16]. However, for a very long BRB, the effective length factor for the boundary element cantilever approaches 2.0. For members where the BRB length is greater than 5 times the connection length, an effective length factor equal to 2.25 is sufficient. Again, to account for uncertainties, the applied force should be less than 1/3.5 times the theoretical buckling axial force.

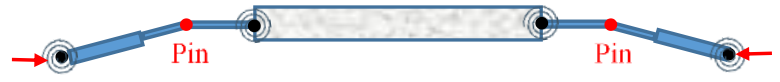

(a) Symmetric buckling

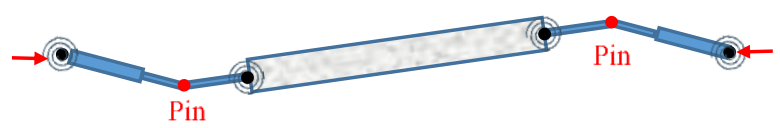

(b) Anti-symmetric buckling

Figure 11: Global buckling modes.

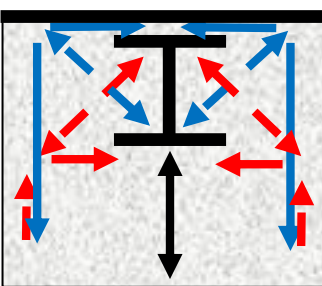

(a) Exterior side connection

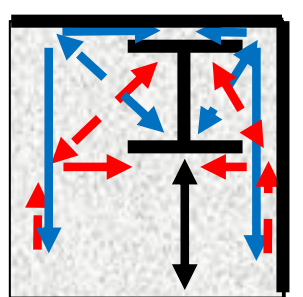

(b) Exterior corner column
Figure 12: Plan of slab strut and tie mechanisms to restrain column twist.

For the floor diaphragm to provide restraint, it must have the necessary stiffness/strength. This can be provided with a thick reinforced slab surrounding the column. Figure 12 gives some strut and tie examples to limit slab-column relative translation and twist. Here, concrete compression forces shown by the continuous lines are in equilibrium with reinforcing steel tension shown by the dashed lines. The blue and red lines 
indicate the slab moving toward the bottom and top of the plan figure relative to column respectively. Reinforcing steel is shown all the way around the column making relative movement/twist difficult. If slab-column detailing is insufficient to provide restraint at the end of the column, and other mechanisms to provide restraint do not exist, then it is possible that the system will not behave as desired.

\section{IPZ S trength}

In addition to the requirement for stiffness and stability, the brace and elements between the pins (i.e. the IPZ in Figure 5) must be strong enough to maintain the expected mechanism. This may be conducted using capacity design principles, where the maximum possible flexural strength of the SDZ is determined. All other elements of the brace between these SDZs must be strong enough to dependably this moment in addition to other moments from gravity or deformations.

\section{OPZ Strength}

The OPZ also requires a minimum strength. In the critical case that the OPZs remain perpendicular to the floors above and below, the angle of the brace with respect to the end elements, $\theta_{\text {SDZoop, }}$ in Figure 1, may be calculated as the interstorey displacement divided by the brace length between SDZs. This is the angle at the pin/SDZ indicated in Figure 1b. For example, if the frame interstorey drift is $2.5 \%$ say (which is the $\mathrm{NZ} \mathrm{drift}$ limit for structures under the 500 year shaking) with an interstorey height of $3.5 \mathrm{~m}$, then the interstorey displacement is $2.5 \% \times 3.5 \mathrm{~m}=87.5 \mathrm{~mm}$. If the brace length between $\mathrm{SDZs}$ is $5 \mathrm{~m}$, then $\theta_{S D Z o o p}=87.5 \mathrm{~mm} / 5000 \mathrm{~mm}=0.0175 \mathrm{rad}=1.75 \%$. Since the brace axial force pushes here, there is a component of force perpendicular to the end zone equal to $0.0175 P$, where $P$ is the brace force. Zaboli et al. [14] recommend using $0.025 P$, or $2.5 \% P$ for all cases which is slightly more conservative and seems reasonable given brace vibration, localised deformation, and other effects in actual frames otherwise not explicitly considered.

The demands at all locations along the length of the "cantilever" member shown in Figure 8, should consider both of the following effects:

1. the overstrength moment at the $S D Z$, and

2. the force of $2.5 \% P$ applied at the $S D Z$.

Under monotonic loading moment demands acting in different directions and are subtractive when the brace is in compression. However, at the peak OOP drift, when the OOP drift starts to move in the opposite direction the direction of overstrength moment changes and the effects become additive. This also occurs under monotonic loading if the brace is in tension. Therefore using the absolute sum of these quantities is reasonable. The capacity of all elements should be greater than the section capacity reduced due to axial force.

\section{DES IGN EXAMPLE}

A fictitious brace, with a configuration similar to that in Figure 8 , has a casing diameter of $300 \mathrm{~mm}$, an effective casing length, $L_{\text {casing }}$, of 5,000 $\mathrm{mm}$ (see Figure 6), an effective distance from the end of the casing to the SDZ at maximum extension, Lendzone, of $400 \mathrm{~mm}$ say making a total length between the SDZs of $5.8 \mathrm{~m}$. The distance from the SDZ to the location of the slab, $L_{\text {Strut }}$, is $500 \mathrm{~mm}$ say. The BRB core plate is $280 \mathrm{~mm}$ wide with an equivalent thickness of $16 \mathrm{~mm}$ and an ultimate compressive stress of $200 \mathrm{~N} / \mathrm{mm}^{2}$ (causing a maximum compression force estimate of $896 \mathrm{kN}), I_{\text {casing }}$ is $95,900,000 \mathrm{~mm}^{4}, I_{\text {endzone }}$ is $6,960,000 \mathrm{~mm}^{4}$, and $I_{\text {strut }}$ from Figure 8 obtained from one of the methods described above is $5,000,000 \mathrm{~mm}^{4}$, a $S D Z$ plate width of $320 \mathrm{~mm}$, SDZ thickness, $t_{S D Z}$, of $20 \mathrm{~mm}$, SDZ plate yield stress of $300 \mathrm{~N} / \mathrm{mm}^{2}$, SDZ plate maximum effective bending stress of $400 \mathrm{~N} / \mathrm{mm}^{2}$, and SDZ length, $l_{S D Z}$, of $40 \mathrm{~mm}$. If $\theta_{\text {oop }}=1.5 \%, \theta_{\text {SDZoop }}=1.5 \%, \delta_{y}=0.0015, \alpha=576 \mathrm{kN} /(320 \mathrm{~mm}$ x $20 \mathrm{~mm} \times 300 \mathrm{~N} / \mathrm{mm}^{2}$ ) $=0.30$, as described in the example above, then:

1. SDZ slenderness check

$\frac{l_{S D Z}}{t_{S D Z}}=\frac{40 \mathrm{~mm}}{20 \mathrm{~mm}}=2$

OK

2. SDZ strain check

$\varepsilon_{S D C \text {,monotonic }}=0.00420<0.015$

OK

(as per example above)

3. BRB buckling considerations from Equation 3,

$r=\frac{E I_{\text {endzone }}}{E I_{\text {casing }}}=\frac{E\left(6,960,000 \mathrm{~mm}^{4}\right)}{E\left(95,900,000 \mathrm{~mm}^{4}\right)}=0.073$

$S=\frac{L_{\text {casing }}}{L}=\frac{5,000 \mathrm{~mm}}{5,800 \mathrm{~mm}}=0.862$

$f=1.182$

$\alpha_{0}=0.775$

$\alpha=0.916$

$P_{c r 1}=\frac{\alpha \pi^{2} E I_{\text {casing }}}{L^{2}}=\frac{(0.916) \pi^{2}\left(200,000 \frac{\mathrm{N}}{\mathrm{mm}^{2}}\right)\left(95,900,000 \mathrm{~mm}^{4}\right)}{(5800 \mathrm{~mm})^{2}}$

$P_{c r l}=5155 \mathrm{kN}$

4. End support buckling considerations, as described above Figure 11,

$P_{c r 1}=\frac{\pi^{2} E I_{\text {strut }}}{\left(k_{\text {eff }} L_{\text {strut }}\right)^{2}}=\frac{\pi^{2}\left(200,000 \frac{\mathrm{N}}{\mathrm{mm}^{2}}\right)\left(5,000,000 \mathrm{~mm}^{4}\right)}{(2.25 \times 500 \mathrm{~mm})^{2}}$

$P_{c r 1}=8000 k N$

The critical elastic buckling load from steps 3 and 4 is 5,155 $\mathrm{kN}$, and the brace itself governs. The allowable axial force is therefore $5,155 / 3.5=1,473 \mathrm{kN}$.

Since this is bigger than $896 \mathrm{kN}$, brace instability is not likely to be an issue, and large frame out-of-plane deformations may be experienced without detrimentally affecting the frame performance.

5. The SDZ moment, $M_{S D Z}$, is given below where the brace overstrength factor, $\phi_{0}$, is 1.25 :

$$
\begin{aligned}
M_{S D Z} & =\frac{b t^{2}}{4} \emptyset_{o} f_{\text {max }}=\frac{(320 \mathrm{~mm})(20 \mathrm{~mm})^{2}}{4}(1.25)\left(400 \frac{\mathrm{N}}{\mathrm{mm}^{2}}\right) \\
& =16 \times 10^{6} \mathrm{Nmm}=16 \mathrm{kNm}
\end{aligned}
$$

All elements of the brace along the length need to be greater than this value.

6. The flexural demand in the OPZ (on the far side of the SDZ from the brace), where $x$ is the distance from the SDZ, is:

$$
\begin{aligned}
& M=M_{S D Z}+2.5 \% P x \\
& M=16 k N m+0.025(896 k N)(x) \\
& \text { E.g when } x=0.5 \mathrm{~m}, \\
& M=27.2 \mathrm{kNm}
\end{aligned}
$$

\section{DIFFERENCES FROM CBF METHODOLOGY}

The proposal described above uses the deformation zone concept developed previously for concentrically braced frame $(\mathrm{CBF})$ gusset plates. However, there are differences in the BRB frames and CBFs, both behaviour and detailing.

- Behaviour: Flexural yielding in gusset plates of BRB frames occurs due to out-of-plane deformations. For CBFs, yielding may also occur at the centre of the braces and in the gusset plates as the braces buckle out-of-plane under large compressive deformations.

- Detailing of deformation zone: The detailing proposed in this paper for BRB gusset plates is more explicit (including consideration of the SDZ buckling, SDZ inelastic demands, and location of the SDZ) than it is for CBFs. 
There are also some similarities between requirements for BRB frames and for CBFs. Both require:

- a strength hierarchy such that the ends of the brace elements must be strong enough to prevent y ielding outside the SDZ, and

- sufficient column torsional stiffness is required to prevent an overall buckling mechanism.

Explicit checks are seldom undertaken to prevent undesirable behaviour related to both these issues even in standard CBF design. The concepts described in this paper therefore provide a better understanding of behaviour from which $\mathrm{CBF}$, as well as BRB frame, construction can benefit.

\section{CONCLUSIONS}

This paper describes the behaviour of Buckling Restrained Braces (BRBs) within frames considering frame out-of-plane deformations and stability. It is shown that:

1. For a BRB frame with significant boundary element (gusset plate/beam/column) out-of-plane restraint, a rotational hinge is required at each end of the BRB member to accommodate out-of-plane lateral deflection without causing flexural stress in the brace itself. Three rotational hinges within the member cause a mechanism.

2. A new concept is proposed for the design of BRBs. The concept, which builds on similar ideas for CBFs, allows large frame out-of-plane deformations without a buckling failure at the BRB member end. Rotational hinges are provided at both ends of the brace. These may be perfect hinges, or weak "poor mans" plastic hinges. These provide a specified deformation zone (SDZ) away from the BRB casing. The moment capacity of the SDZ is small, so moments applied to the brace are small. This means that the brace's cyclic deformation capacity should not decrease, nor axial compression strength increase, significantly during frame out-of-plane deformations. Capacity design is used to ensure that BRB end zone remains elastic so that the BRB has repeatable in-plane performance. Boundary elements (beams-columns and gusset plates) are designed to provide sufficient lateral stiffness and strength at the locations of the pins/hinges to prevent instability.

3. Stiffness/stability and strength requirements for elements of the BRB system (i) between the locations of pins/hinges considering casing end flexibility, and (ii) outside the pins, are proposed. Guidance is given as to how boundary element restraint may be provided by a floor slab.

4. Frame out-of-plane deformation capacity is limited by the strains in the SDZ. A simple method is provided to assess this effects.

5. A number of details are required for good performance. The SDZ must be detailed so that deformation occurs reliably there. This may require gusset plate stiffeners. Vertical and horizontal stiffeners may be required in the beam and column respectively near the edge of the gusset plate depending on the load path considered. Boundary element restraint may be provided by a reinforced concrete floor slab wrapping around the column.

\section{ACKNOWLEDGEMENTS}

The authors wish to thank the MBIE Natural Hazards Research Programme Research Objective 4 (New Buildings) for sponsoring the fourth author and the University of Canterbury for providing support for the fifth author. Support of the NZ Heavy Engineering Educational Research Fund and the Department of Civil and Natural Resources Engineering at the University of Canterbury for work conducted by both the third and fourth authors is appreciated. The third author is also grateful to funding from National Council of Science and Technology of Mexico (CONACyT). The sponsorship above was part of the catalyst for the ideas produced in this paper. The authors thank Charles Clifton for discussions about a reasonable maximum fraction of the Euler load to be considered in design. Also, the three anony mous reviewers made excellent comments which have increased the quality of the paper. In particular, one reviewer emphasized the need for a strength check at the maximum out-of-plane deformation which has been included in the paper. The opinions expressed in this paper are those of the authors alone.

\section{REFERENCES}

1 MacRae G (2014). "BRB Issues, Email to Engineer". https://www.dropbox.com/s/aw5e0znnkhy 5mr3/BRB\%20I ssues anony mised.pdf?dl=0

2 MacRae GA and Clifton GC (2015). "NZ research on steel structures in seismic areas". 8th International Conference on Behaviour of Steel Structures in Seismic Areas (STESSA), July 1-3, Shanghai, China, pp. 44-58.

3 MacRae G (2016). Considerations for BRB Design, ENCI650 Class Notes. University of Canterbury. https://www.dropbox.com/s/y 50hwkax0nnf41j/L11 09 B RB\%20Design\%20Considerations\%20_\%20MacRae\%20J une $\% 202016 \% 2 \mathrm{~B} 2019 . \mathrm{pdf} ? \mathrm{dl}=0$

4 Hariri B and Tremblay R (2019). "Stability of BRB frames under long duration subduction earthquakes". 12th Canadian Conference on Earthquake Engineering, June 17-20, Quebec, Canada, Poster Code: CEISCE-26.

5 Palmer KD, Roeder CW and Lehman DE (2016). "Connection design recommendations for improved BRBF performance". Engineering Journal, American Institute of Steel Construction, 53: 29-45.

6 Sitler B, MacRae G, Takeuchi T, Matsui R, Westeneng B and Jones A (2017). "BRB performance issues". 16th World Conference on Earthquake Engineering (16WCEE), January 9-13, Santiago, Chile, Paper No 1380.

7 Westeneng B, Lee C-L, MacRae GA and Jones A (2017). "Out-of-plane buckling behaviour and design of BRB gusset plate connections". 16th World Conference on Earthquake Engineering (16WCEE), January 9-13, Santiago, Chile, Paper No 1419.

8 AISC (2016). "ANSI/AISC 341-16: Seismic Provisions for Structural Steel Buildings". American Institute of Steel Construction, Chicago.

9 Cui J (2020). “BRB Performance Issues”. PhD Thesis, University of Canterbury, Christchurch, New Zealand.

10 Cui J, Lee C-L and MacRae G (2019). "Strong-axis and weak-axis buckling of buckling restrained braces under bidirectional loading". Pacific Conference on Earthquake Engineering, April 4-6, Auckland, New Zealand.

11 Ozaki H, Konishi Y, Matsui R and Takeuchi T (2014). "Out-Of-plane stability factors for diagonally installed buckling restrained braces". Journal of Structural and Construction Engineering, 79(706): 1919-1929. (in Japanese)

12 Takeuchi T, Ozaki H, Matsui R, and Sutcu F (2014). "Outof-plane stability of buckling-restrained braces including moment transfer capacity". Earthquake Engineering and Structural Dynamics, 43(6): 851-869. https://doi.org/10.1002/eqe.2376

13 Takeuchi T and Matsui R (2017). "State-of-art stability assessment of buckling-restrained braces". 16th World Conference on Earthquake Engineering (16WCEE), January 9-13, Santiago, Chile, Paper No 602. 
14 Zaboli B, Clifton GC and Cowie K (2018). "BRBF and CBF gusset plates: out-of-plane stability design using a simplified notional load yield line (NLYL) method". SESOC Journal, 31(1).

https://www.sesoc.org.nz/library/sesoc-journals/vol-3135/\#squelch-taas-accordion-shortcode-content-9

15 Bruneau M and Wei X (2017). "Experimental performance of buckling restrained braces subjected to bidirectional displacement histories". 16th World Conference on Earthquake Engineering (16WCEE), January 9-13, Santiago, Chile, Paper No 819.

16 Alizadeh S, MacRae GA, Bull D and Clifton C (2018). "Beam web-side-plate connection axial performance". Key Engineering Materials, 763: 174-181. https://doi.org/10.4028/www.scientific.net/KEM.763.174

17 MacRae GA, Urmson CR, Walpole WR, Moss P, Hyde K and Clifton GC (2009). "Axial shortening of steel columns in buildings subjected to earthquakes". Bulletin of the NZ Society of Earthquake Engineering, 42(4): 275-287. https://doi.org/10.5459/bnzsee.42.4.275-287
18 Lee S and Goel SC (1987). "Seismic Behavior of Hollow and Concrete-Filled Square Tubular Bracing Members" Report No. UMCE 87-11, University of Michigan, Department of Civil Engineering, Ann Arbor, MI.

19 SNZ (2007). "NZS 3404: New Zealand Steel Structures Standard (\& Commentary) with Amendments 1 and 2". Standards New Zealand, Wellington.

20 Hughes AF, Iles DC and Malik AS (2011). "Design of Beams in Torsion”. SCI Publication 385, 71 pp. https://www.steelconstruction.info/images/6/6f/Sci p385. $\underline{\mathrm{pdf}}$

21 Engineering ToolBox (2009). Beams - Supported at Both Ends - Continuous and Point Loads. https://www.engineeringtoolbox.com/beam-stressdeflection-d 1312.html [Accessed 03 August 2019].

22 Gstatic (2019). Universal Joint Image. https://encryptedtbn0.gstatic.com/images?q=tbn:ANd9GcRdpe_DupM6JFVQU3s4mPkC2wVolieSqCCuW ci jSTxvamkwA, (Retrieved 29 July 2019) 